ASM Sc. J., 13, 2020

https://doi.org/10.32802/asmscj.2020.sm26(2.12)

\title{
Electrical Simulation for Different Thickness Ratio of PCBM and PTAA in Bilayer Organic Solar Cells
}

\author{
Norjannah Yusop ${ }^{1}$, Chee Fuei Pien ${ }^{1}$, Afishah Alias ${ }^{2}$, Abu Bakar Abd Rahman ${ }^{1}$ and Abdul Ismail \\ Abdul Rani3 \\ ${ }^{1}$ Faculty of Science and Natural Resources, Universiti Malaysia Sabah, \\ 88400 Kota Kinabalu, Sabah, Malaysia \\ ${ }^{2}$ Faculty of Applied Science and Technology, Universiti Tun Hussien Onn Malaysia, \\ 86400 Parit Raja, Johor \\ ${ }^{3}$ School of Engineering \& Technology, University College of Technology Sarawak, \\ No 1 Jalan Universiti, Sibu Sarawak
}

\begin{abstract}
In organic solar cells, it is regularly observed that different thickness of active layer result in different competency of the device due to its behaviour of charge transportation and charge collection in such volume morphology of active layer. In this paper, heterojunction device based on poly(triarylamine) (PTAA) and [6,6]-phenyl- $\mathrm{C}_{61}$-butyric acid methyl ester (PCBM) as active layer had been electrically characterized using general -purpose photovoltaic device model (GPVDM) software. A thickness ratio: 50:50, 100:50,150:50, and 250:50 nm of PTAA to PCBM and vice versa for PCBM to PTAA were evaluated in this simulation. This simulation displays a pattern of current-voltage $(I-V)$ and current density-voltage $(J-V)$ at different thickness for PTAA/PCBM heterojunction bilayer solar cells. The short circuit current density $\left(J_{\mathrm{sc}}\right)$, open circuit voltage $\left(V_{\mathrm{oc}}\right)$ and fill factor $(F F)$ for each different thickness active layer device was also presented as well. The highest achievable efficiency, $9.283 \%$ was observed at thickness ratio of 250: $50 \mathrm{~nm}$ (PTAA to PCBM) under light intensity of $10 \mathrm{~mW} / \mathrm{cm}^{2}$.
\end{abstract}

Keywords: heterojunction devices; PTAA; PCBM; GPVDM; solar cells

\section{INTRODUCTION}

Organic semiconductor materials have the capability of transporting charge carriers and had been studied since 1950. Organic material is accepted as active materials in semiconductor devices due to their notable of development in many photonic applications, such as organic field-effect transistors (OFET), organic light-emitting diode (OFET), and organic solar cells (OSC) (Chen et. al., 2009). Organic semiconductors have special characteristics such as light in weight, simple of production, and the price is relatively low (Kawano, Sakai, Yahiro, \& Adachi, 2009).
An organic semiconductor can be classified into two categories known as small molecules and polymers. Usually the organic small molecule is compound contain carbon atom that are bonded into stable individual molecular unit. Both PCBM/PTAA of active layer that used in the simulation are classified as small molecule (Lin et. al., 2014). Recently, the heterojunction of electron donor molecule and functionalized fullerene as electron acceptors have revolutionizes over the silicon based photovoltaic cells (Ramrakhiani, 2017). In an experimental data, the bilayered of heterojunction of an electron donate and fullerene electron acceptor can be employed in organic photovoltaic

*Corresponding author's e-mail: jannahjan@ymail.com 
device as its more straightforward, facilitating optimization as compared with bulk heterojunction PVC. However, the exciton dissociation efficiency in bilayer device is lower than that of reported bulk heterojunction photovoltaic cells (Ramrakhiani, 2017). Hence, a group of researchers had proposed few methods to produce bilayer solar cells with better characteristics includes increasing the interface area of electrons and holes diffusion and also enhancing exciton dissociation (He et. al., 2011).

Aim of this GPVDM simulation is to investigate the relationship between thicknesses of active layers towards its electrical characteristics. Performance of solar cell was strongly depending on the thickness of active layers which is related to the inter diffusion of the charge from hole transport layer towards the electron transport layer. The most favourable morphological volume of donor and acceptor material ensures movement of charge carrier paths to both electrodes and thus confines the potential for charge recombination (Intaniwet et. al., 2009; Narayan, 2012)]. Results of this simulation can be used to design an experimental in fabricating bilayer organic devices of high efficiencies with less production time and costs.

\section{THEORETICAL EQUATIONS}

Short circuit current density, $J_{s c}$ (Ong \& Levitsky, 2010) can be derived from equation (1)

$$
\begin{gathered}
J_{s c}=\frac{I_{s c}}{A} \\
I_{s c}=q G\left(L_{n}+L_{p}\right)
\end{gathered}
$$

where $I_{s c}$ is short circuit current, A is the area of the layer, $G$ is the generation rate, $L_{n}$ and $L_{p}$ is the diffusion length for electron and hole.

However, the short circuit current density $J_{s c}$ (Nath et al. 2011) can be theoretically determined as

$$
J_{s c}=q \int_{\lambda} b_{s}(\lambda) Q E(\lambda) d \lambda
$$

Where $b_{s}(\lambda)$ is the incident photon flux density and $Q E(\lambda)$ is the quantum efficiency $(Q E)$ of the cells at given wavelength, $\lambda$. $Q E$ is the quantum efficiency refers to amount of carries collected at the electrode to the amounts of photons of given energy incident.
Fill factor is determined as

$$
F F=\frac{V_{m p p} J_{m p p}}{V_{o c} J_{s c}}
$$

where $V_{m p p}$ is the maximum power point in graph, $J_{m p p}$ is the maximum power point for short circuit current. The stated equation resolving, and device modelling have been applied in research of (Narayan, 2012; T et. al., 2016; Tsoi et. al., 2011) for photovoltaic devices.

The power conversion efficiency $(\eta)$ of organic solar cells can be expressed as

$$
\eta=\frac{F F \cdot V_{o c} \cdot J_{s c}}{P_{i n}}
$$

where, $\mathrm{P}_{\text {in }}$ is the light incident power density. $V_{o c}$ is the open circuit voltage where the organic solar cells produced maximum voltage as the short circuit current density $J_{s c}$ is zero under illumination is zero.

\section{SIMULATION PARAMETERS}

Figure 1 shows the structure of simulated bilayer solar cells. The device structure is split up into different materials consists small molecule as active layers. Electron transport material layer is the fullerene derivatives, [6,6]-Phenyl $\mathrm{C}_{61}$ butyric acid methyl ester, PCBM was reported to have higher efficiencies in organic solar cells and the Hole transport material layer, Poly(triarylamine), PTAA act as layer over which the electric model will be applied. Both thickness of active layer was manipulated using GPVDM software under $10 \mathrm{~mW} / \mathrm{cm}^{2}$ light intensity. First simulation of this configuration was focused on different thickness of PTAA at 50nm, 100nm, $150 \mathrm{~nm}$ and $250 \mathrm{~nm}$ respectively at fixed width of PCBM, 50nm. Next simulation was determining the electrical characteristics at different thickness layer PCBM, $50 \mathrm{~nm}$, 100nm, 150nm and $250 \mathrm{~nm}$ at 5Onm of PTAA. The depth of electrode ITO and Al were fixed at 10onm. The configuration of devices as shown in Table 1.

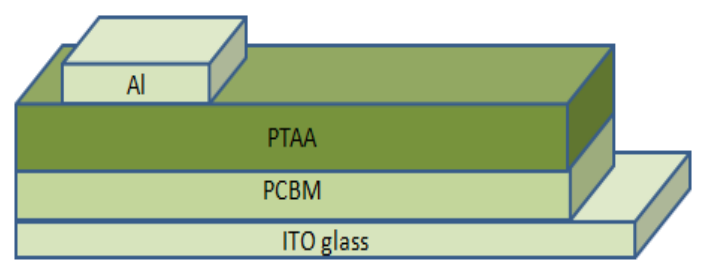

Figure 1. Structure of bilayer organic solar cells for GPVDM simulation 
Table 1. The parameter configuration in applied GPVDM simulation of organic bilayer solar cell

\begin{tabular}{|l|c|c|}
\hline PARAMETER & $\begin{array}{l}\text { PARAMETER'S } \\
\text { VALUE }\end{array}$ & UNITS \\
\hline $\begin{array}{l}\text { Electron trap } \\
\text { density }\end{array}$ & $1 \mathrm{e} 25$ & $\mathrm{~m}^{-3} \mathrm{eV}^{-1}$ \\
\hline Hole trap density & $1 \mathrm{e} 25$ & $\mathrm{~m}^{-3} \mathrm{eV}^{-1}$ \\
\hline Electron Mobility & $1 \mathrm{e}-6$ & $\mathrm{~m}^{2} \mathrm{~V}^{-1} \mathrm{~s}^{-1}$ \\
\hline Hole mobility & $1 \mathrm{e}-6$ & $\mathrm{~m}^{2} \mathrm{~V}^{-1} \mathrm{~s}^{-1}$ \\
\hline $\begin{array}{l}\text { Trapped electron to } \\
\text { free hole }\end{array}$ & $1 \mathrm{e}-22$ & $\mathrm{~m}^{-2}$ \\
\hline $\begin{array}{l}\text { Trap hole to free } \\
\text { electron }\end{array}$ & $1 \mathrm{e}-22$ & $\mathrm{~m}^{-2}$ \\
\hline $\begin{array}{l}\text { Free electron to } \\
\text { trapped electron }\end{array}$ & $1 \mathrm{e}-21$ & $\mathrm{~m}^{-2}$ \\
\hline $\begin{array}{l}\text { Free hole to } \\
\text { trapped hole }\end{array}$ & $1 \mathrm{e}-21$ & $\mathrm{~m}^{-2}$ \\
\hline Device witdh & 0.01 & $\mathrm{~m}$ \\
\hline
\end{tabular}

\section{RESULTS AND DISCUSSION}

Figure 2 presents the I-V characteristics of the simulated device at different thickness of PCBM / PTAA. The device shows a highest current produced when thickness of PCBM at 250nm and PTAA at 50nm. PCBM can trap more electron charge to be diffused at electrode as the layer become thicker. However, at thickest layer of PTAA, the total current at $4 \mathrm{~V}$ is slightly lower, $0.037 \mathrm{~A}$, this indicate some of $\mathrm{e}^{-}$is not able to be discharge at the electrode. The atomic structure of PTAA itself allowed the rate of exciton recombination become faster. However, as the thickness of PTAA increases, the photon is absorbed at higher rate causes the rate of exciton recombination at phases also increases (Lin et al., 2014). Both graph shown in figure 2 (a) and 2 (b) indicates that at 0.00 to $0.60 \mathrm{~V}$, the current values was nearly to be constant where at $\mathrm{V}=0$, the $\mathrm{I}=-0.00208 \mathrm{~A}$ and $-0.00187 \mathrm{~A}$ for PCBM and PTAA thickness at $250 \mathrm{~nm}$ respectively, this values is known to be the short circuit current. The point at $\mathrm{V}=0.60 \mathrm{~V}$, there was a sudden increase in current from both graphs represented as "knee" point (Ramrakhiani, 2017).

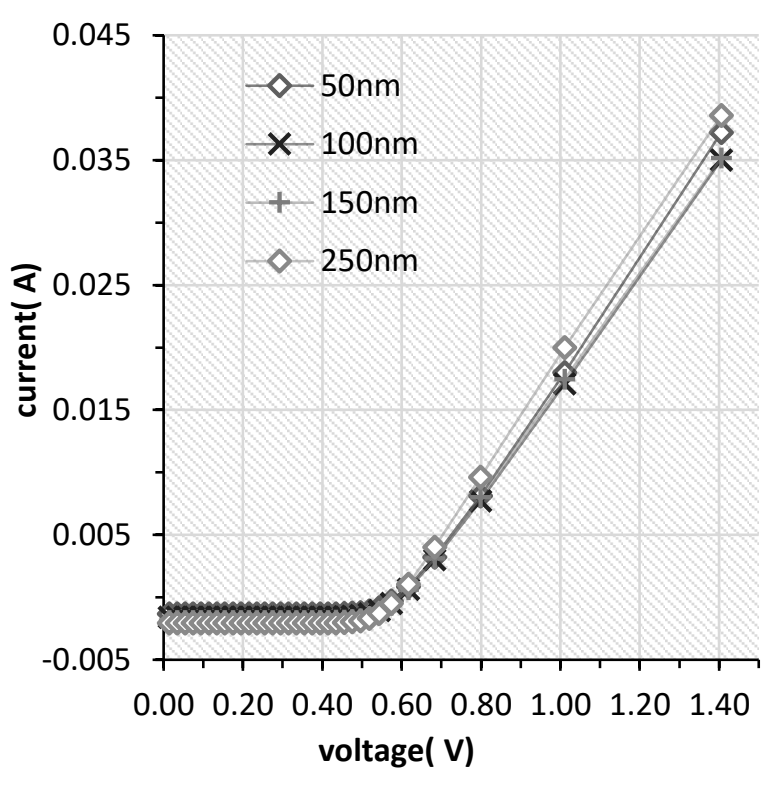

Figure 2(a). I-V characteristics of organic bilayer PCBM/PTAA at vary thickness of PCBM

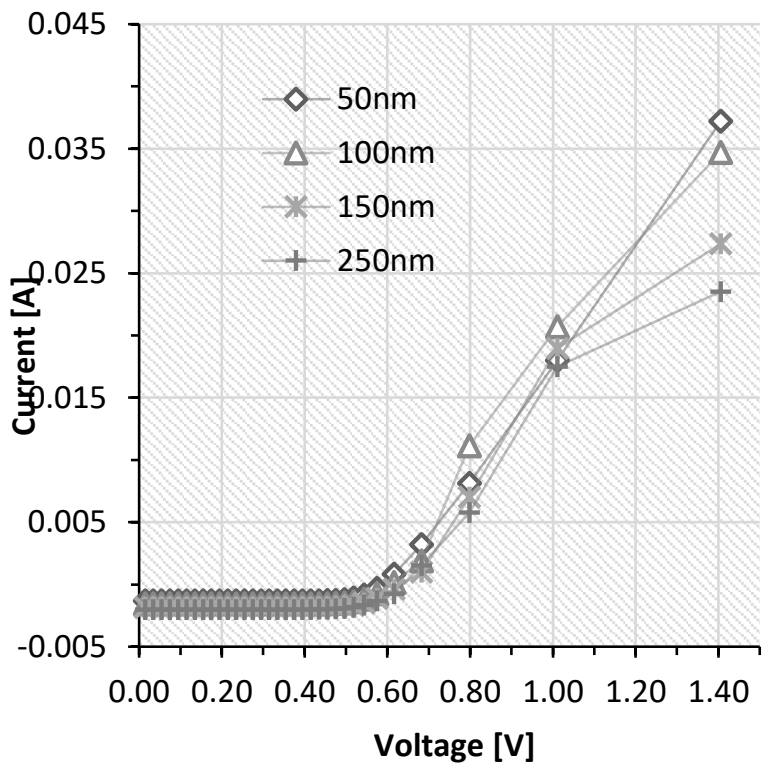

Figure 2(b). I-V characteristics of organic bilayer PCBM/PTAA at vary thickness of PTAA

Figure 3 shows the influence of layer thickness on $J_{s c}$ for both configurations of solar cells. A thick layer enables more electron and holes trapping in film along with great photons absorbed to induce exciton dissociation at the interface (Kawano et al. 2009). The short circuit current density, $J_{s c}$ for both configurations shows to have elevated value as thickness of active layer increases. It is observed the highest value of $J_{s c}$ by $0.208 \mathrm{~mA} / \mathrm{cm}^{2}$ at thickness ratio 250nm:50nm of PCBM to PTAA. In most of experimental data, thicker active film formed a reduction of short current density due to non-ideal surrounding environment during 
the process of solar cells fabrication (T et. al., 2016). In this simulation, the $J_{\mathrm{sc}}$ is increasing linearly with the active layer to indicate that almost all the photogenerated electron hole pair contribute to $J_{\mathrm{sc}}$ since they are succeeded to be collected at electrode before the recombination occurs (Chopra, 2011)

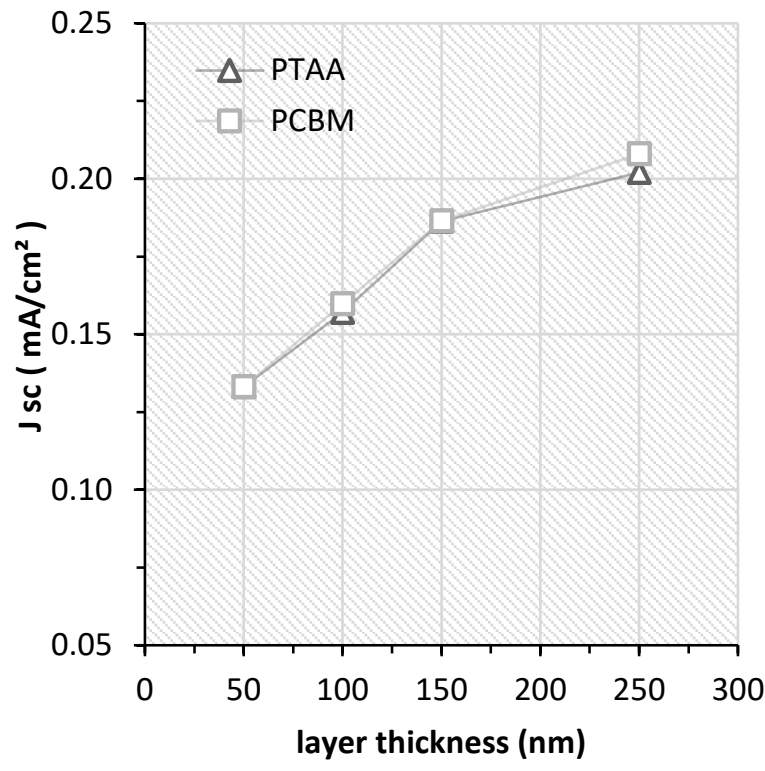

Figure 3. Device Short Circuit, $J_{s c}$ at different thickness ratio of active layer

It is remarkable that the values of open circuit voltage also increase as the thickness layers for both configurations was increases, where thickest layer of PTAA gave significant effect to its electrical characteristics as compared with the thickest layer of PCBM. Open circuit voltage determined the voltage produced at solar cell junction when the forward biased current is zero. Figure 4 demonstrates the influence of layer thickness on open circuit voltage, $V_{\text {oc }}$ of the simulated module. $0.616 \mathrm{~V}$ is the highest $\mathrm{V}_{\text {oc }}$ obtained from configuration of PCBM/ PTAA layers at thickness ratio of 50nm: 250nm. A study by Hsiang-Yu Chen et al. 2009 state that the values of $\mathrm{V}_{\mathrm{oc}}$ was depends on the difference of HOMO level of e- donor and LUMO level of e- acceptor, lowering the differences will exhibit an increase the open circuit voltage (Chen et al. 2009). However, the $\mathrm{V}_{\text {oc }}$ in vary thickness of PCBM is lower compared to PTAA and the reasons by a smaller band gap is not very clear for this simulation. Large amount for crystalline volume fraction $\left(\mathrm{F}_{\mathrm{c}}\right)$ was remarked to low values in Open circuit voltage of PCBM as compared with PTAA.

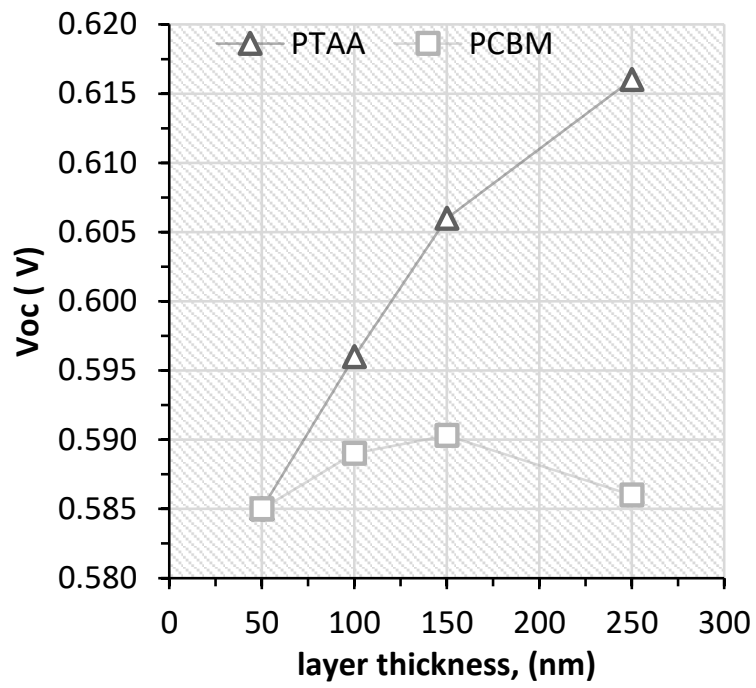

Figure 4. Device Open Circuit voltage, $V_{o c}$ at different thickness ratio of active layer

Obviously, an increase in the thickness active layer both configurations had influenced the fill factor of the solar cells. At a thickness ratio 50nm:50nm for PTAA / PCBM, its yield 0.780 a.u of fill factor $(F F)$ to provide more power under normal operating conditions. The variation in fill factor values indicates a change in series resistance of electron transport layer, where charge extraction at electrode increases as series resistance from a thin layer of PCBM was reducing (Narayan, 2012). The imbalanced charge extraction rates for the hole and the electrons also cause the fill factor, $F F$ to decreases in thicker film (Lin et al. 2014). Figure 5 shows the influence of active layer thickness on fill factor, $F F$ for both configurations of bilayer organic solar cells.

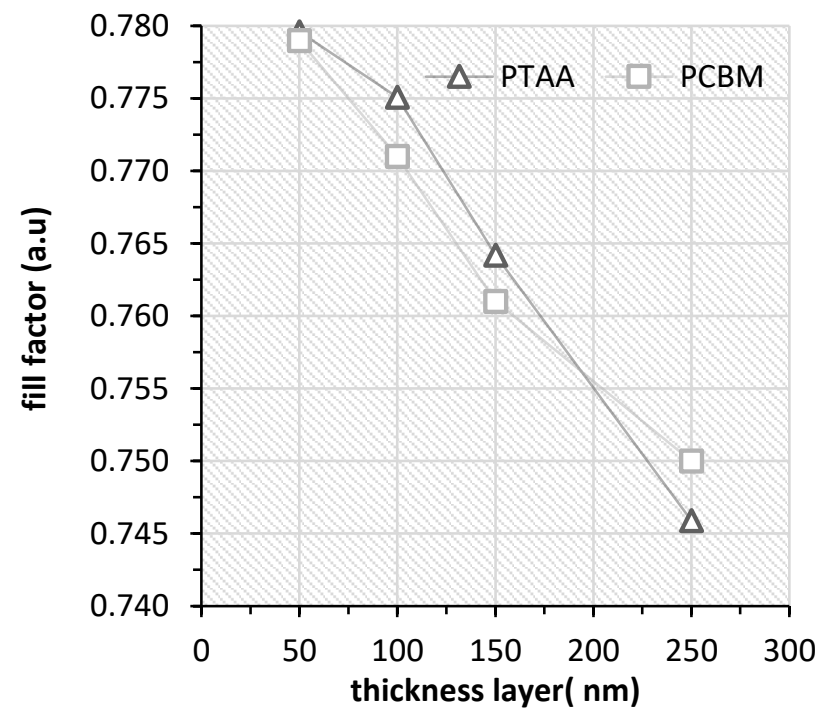

Figure 5. Device fill factor at different thickness ratio of active layer 


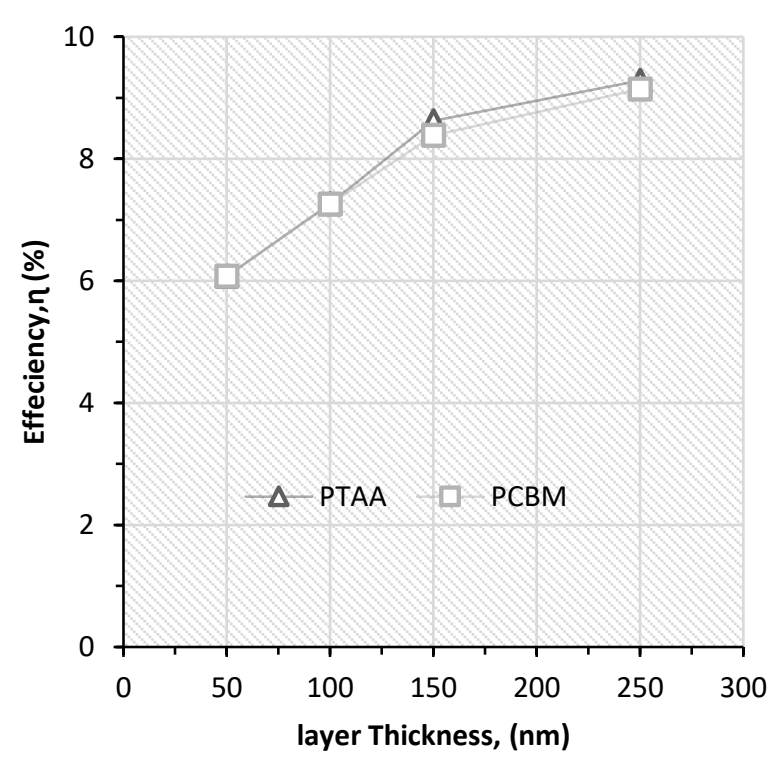

Figure 6. Device efficiency at different thickness ratio of active layer

The effect of active layer thickness on percentage efficiency had been analysed and shown in Figure 6. The thickest layer of hole transport material (PTAA 250nm with PCBM 50nm) had achieved the best efficiencies with 9.283\%. This simulation shows that PCBM at thickest layer (PTAA at 50nm) also able to produces high efficiencies at 9.143\% but slightly lower than the rate achieved by PTAA at $250 \mathrm{~nm}$ (PCBM at 50nm). The thicker active layer allows the formation of a continuous network throughout the entire active layers, created a maximum number of dissociate excitons and delayed the time of charge recombination due to its Columbic attraction at the interface. The combination of materials and different thickness used in this study reveals that depth of layer for holes transport material PTAA ratio can exhibit a better electrical characteristic compared with the changes in PCBM layer thickness. Table 2 and 3 shows the results of electrical simulation on performance of bilayer organic solar cells.

Table 2. The Electrical simulation at different thickness of PTAA at light intensity of $10 \mathrm{~mW} / \mathrm{cm}^{2}$

\begin{tabular}{|c|c|c|c|c|}
\hline $\begin{array}{c}\text { Thickness ratio } \\
\text { PTAA to PCBM } \\
(\mathbf{n m})\end{array}$ & $\begin{array}{c}\boldsymbol{J}_{\mathbf{s c}} \\
(\mathbf{m A} / \\
\left.\mathbf{c m}^{2}\right)\end{array}$ & $\begin{array}{c}\text { Voc } \\
\text { (V) }\end{array}$ & $\begin{array}{c}\boldsymbol{F F} \\
(\end{array}$ & $\boldsymbol{\eta}$ (\%) \\
\hline $50: 50$ & 1.330 & 0.585 & 0.780 & 6.075 \\
\hline $100: 50$ & 1.560 & 0.597 & 0.775 & 7.626 \\
\hline $150: 50$ & 1.860 & 0.606 & 0.764 & 8.670 \\
\hline $250: 50$ & 2.000 & 0.616 & 0.746 & 9.283 \\
\hline
\end{tabular}

Table 3. The Electrical simulation at different thickness of $\mathrm{PCBM}$ at light intensity of $10 \mathrm{~mW} / \mathrm{cm}^{2}$

\begin{tabular}{|c|l|l|l|l|}
\hline $\begin{array}{c}\text { Thickness } \\
\text { ratio PCBM to } \\
\text { PTAA (nm) }\end{array}$ & $\begin{array}{l}\boldsymbol{J}_{\text {sc }} \\
(\mathbf{m A} / \\
\left.\mathbf{c m}^{2}\right)\end{array}$ & $\begin{array}{l}V_{\text {oc }} \\
(\mathbf{V})\end{array}$ & $\begin{array}{l}\boldsymbol{F F} \\
\mathbf{( a . u )}\end{array}$ & $\boldsymbol{\eta ( \% )}$ \\
\hline $50: 50$ & 1.331 & 0.585 & 0.780 & 6.075 \\
\hline $100: 50$ & 1.598 & 0.589 & 0.771 & 7.260 \\
\hline $150: 50$ & 1.867 & 0.590 & 0.761 & 8.385 \\
\hline $250: 50$ & 2.080 & 0.587 & 0.750 & 9.143 \\
\hline
\end{tabular}

\section{CONCLUSION}

Electrical characteristics of organic bilayer solar cell at different thickness ratio of PCBM/PTAA were analysed using the GPVDM solar cells software simulation. This software simulation is using numerical modelling reveals that the thicker layer of active layer yields a maximum efficiency of 9.283\%. The change in the PTAA thickness shows more significant effect in the optical absorption when being compared to PCBM as its shows a higher value of open circuit voltage.

\section{ACKNOWLEDGEMENT}

This work is supported by the Ministry of Higher Education Fundamental Research Grant Scheme (FRGS) 2016 under the scheme FRGS/1/2016/STG02/UMS/02/2 with title "Investigation of Damage Mechanism of Zinc Oxide Thin Film Transistors (ZnO TFTs) due to neutron Radiation for Flexible Electronic in Space Application and University Malaysia Sabah under UMSGREAT Grant (GUGo203) with title Morphology and Electrical Characteristics of $\mathrm{PCBM} / \mathrm{ZnO}$ based heterojunction Devices. 


\section{REFERENCES}

Chen, H. Y., Hou, J., Zhang, S., Liang, Y., Yang, G., Yang, Y., ... Li, G. 2009, Polymer solar cells with enhanced opencircuit voltage and efficiency. Nature Photonics, 3(11), pp. 649-653.

Chopra, K. L. 2011, Thin Film Solar cells: a status review. Center of Excellence in Nanotechnology - KFUPM, pp. $3-50$.

He, Z., Zhong, C., Huang, X., Wong, W. Y., Wu, H., Chen, L., ... Cao, Y. 2011, Simultaneous enhancement of opencircuit voltage, short-circuit current density, and fill factor in polymer solar cells. Advanced Materials, 23(40), pp. $4636-4643$.

Intaniwet, A., Mills, C. A., Shkunov, M., Thiem, H., Keddie, J. L., \& Sellin, P. J. 2009, Characterization of thick film poly(triarylamine) semiconductor diodes for direct $x$-ray detection. Journal of Applied Physics, 106, pp. 064513.

Kawano, K., Sakai, J., Yahiro, M., \& Adachi, C. 2009, Effect of solvent on fabrication of active layers in organic solar cells based on poly(3-hexylthiophene) and fullerene derivatives. Solar Energy Materials and Solar Cells, 93(4), pp. 514-518.

Lin, X., Seok, J., Yoon, S., Kim, T., Kim, B., \& Kim, K. 2014, Morphological investigation of $\mathrm{P}_{3} \mathrm{HT} / \mathrm{PCBM}$ heterojunction and its effects on the performance of bilayer organic solar cells. Synthetic Metals, pp. 196, $145^{-150 .}$

Narayan, M. R. 2012, Review: Dye sensitized solar cells based on natural photosensitizers. Renewable and Sustainable Energy Reviews, 16(1), pp. 208-215.
Nath, M., Chakraborty, S., Johnson, E. V, Abramov, A., Roca I Cabarrocas, P., \& Chatterjee, P. 2011, EPJ Photovoltaics EPJ Photovoltaics Factors limiting the open-circuit voltage in microcrystalline silicon solar cells. EPJ Photovoltaics, 2, pp. 20101.

Ong, P. L., \& Levitsky, I. A. 2010, Organic / IV, III-V semiconductor hybrid solar cells. Energies, 3(3), pp. $313-334$

Ramrakhiani, M. 2017, Recent Advances in Photovoltaics. Materials Research Forum LLC.

T, S., B, A., A, A., R, B., H, B., \& B, K. 2016, High Fill Factor and Conversion Efficiency in Organic Photovoltaic Cells with PEDOT: PSS / C6o. Ijarcce, 5(11), pp. 1-3.

Tsoi, W. C., Spencer, S. J., Yang, L., Ballantyne, A. M., Nicholson, P. G., Turnbull, A., ... Kim, J. S. 2011, Effect of crystallization on the electronic energy levels and thin film morphology of $\mathrm{P}_{3} \mathrm{HT}: \mathrm{PCBM}$ blends. Macromolecules, 44(8), pp. 2944-2952. 